\title{
CLINICO-EPIDEMIOLOGICAL PROFILE AND OUTCOME OF CASES OF HYDATID CYST- A PROSPECTIVE AND RETROSPECTIVE STUDY
}

\author{
Arvind Kumar Shukla1, Varsha Dhakad², Mumtaz Ansari ${ }^{3}$
}

${ }^{1}$ Associate Professor, Department of General Surgery, MYH Hospital, Indore, Madhya Pradesh, India.

${ }^{2}$ Associate Professor (Designated), Department of General Surgery, MYH Hospital, Indore, Madhya Pradesh, India.

3Junior Resident, Department of General Surgery, MYH Hospital, Indore, Madhya Pradesh, India.

\section{BACKGROUND}

ABSTRACT

Hydatid cyst is the most common cause of cystic Liver disease world-wide. Hydatid disease is a zoonoses caused by small taeniidtype tapeworm Echinococcus. Man is an accidental intermediate and dead end host. Man does not harbour the adult worm.[1]

The objectives of this study were- 1. to compare the treatment of retrospective and prospective cases of hydatid cyst disease \& 2. to study the hydatid cyst disease.[2]

\section{MATERIALS AND METHODS}

The study comprises of all treated cases of hydatid cyst in Dept. of Surgery, M.G.M. Medical College and M.Y Hospital, Indore retrospectively from 2007 to 2017 (100 cases) and prospectively from 1 year after the date of approval (20 cases) by local ethical committee.

\section{RESULTS}

In this study, more than half of the subjects were men with higher prevalence of disease in patients from rural areas. The mean incidence of Hydatid disease is 1.256 per 1000 admissions in general surgical wards. The disease is more prevalent among illiterate people because of more contact with cattle, poor hygiene and sanitation. Liver is the most common site of hydatid cyst disease and mostly cysts are located in the right lobe. ${ }^{2}$

\section{CONCLUSION}

1. High prevalence seen from the districts of Nimar region as compared to Malwa region because of more contact with cattle, low level education, poor sanitation and poor hygiene.

2. CECT of abdomen can be used as a tool for guiding the approach towards surgery, laparoscopic surgery being safe and yielding better results.[3][4]

3. Prevention plays an important in the overall management of this disease. Proper education, creating awareness, deworming of dogs and implementing strict rules regarding the disposal of the remains of slaughtered animals can help in eradicating this disease.

\section{KEY WORDS}

Hydatid CYST, Pericystectomy, Albendazole.

HOW TO CITE THIS ARTICLE: Shukla AK, Dhakad V, Ansari M. Clinico-epidemiological profile and outcome of cases of hydatid cyst- a prospective and retrospective study. J. Evolution Med. Dent. Sci. 2019;8(07):458-462, DOI: 10.14260/jemds/2019/101

\section{BACKGROUND}

Hydatid cyst is the most common cause of cystic liver disease world-wide. Hydatid disease is a zoonoses- a group of cestode infections, caused by small taeniid-type tapeworm Echinococcus. Man is an accidental intermediate host. Man is dead-end host. Man does not harbour the adult worm.

There are 4 Species of Echinococcus which cause hydatid Disease-

- E.granulosus: the most common causative organism worldwide. In man infective larva causes "unilocular" type of echinococcosis.

- E.multilocularis: restricted to northern hemisphere. It causes "alveolar" type of echinococcosis. It has poor prognosis as compared to E.granulosus. [5]

'Financial or Other Competing Interest': None.

Submission 21-12-2018, Peer Review 01-02-2019,

Acceptance 07-02-2019, Published 18-02-2019.

Corresponding Author:

Dr.Varsha Dhakad,

\#48, Pink City Ring Road,

Near Musakhedi, Indore-452020,

Madhya Pradesh, India.

E-mail:drvarshadhakad@gmail.com

DOI: $10.14260 /$ jemds $/ 2019 / 101$

\section{(c) (i) $(9$}

- E.oligarthus.

- E.vogeli: causes polycystic hydatidosis.

\section{Objective}

To compare the treatment of retrospective and prospective cases $\&$ to study the hydatid cyst disease.

\section{MATERIALS AND METHODS}

The study comprises of all treated cases of hydatid cyst in Dept. of Surgery, M.G.M Medical College and M. Y Hospital, Indore retrospectively from 2007 to 2017 (100 cases) and prospectively from 1 year after the date of approval (20 cases) by local ethical committee.

This study was approved by Ethical Committee and it was a part of post graduate dissertation in M. Y. Hospital, Indore.

\section{Duration of study}

10 years.

\section{Study Design}

Observational study.

\section{Study Period}

1 year from the date of approval. 
Place of Study

Department of Surgery, M.G.M medical college and M.Y.

Hospital, Indore.

\section{Sample Size}

Retrospective 100 cases. Prospective 20 cases.

\section{Inclusion Criteria}

- All diagnosed cases of hydatid cyst.

- $\quad$ Age $>18$ years and above.

- Patients who give written informed consent.

\begin{tabular}{|c|c|c|c|c|}
\hline \multirow{2}{*}{ SEX } & \multicolumn{2}{c|}{ Group } & \multirow{2}{*}{ Total } \\
\cline { 3 - 5 } & Count & Retrospective & Prospective & 52 \\
\cline { 2 - 5 } \multirow{2}{*}{ Female } & $\%$ & $42.0 \%$ & $50.0 \%$ & $43.3 \%$ \\
& Count & 58 & 10 & 68 \\
\multirow{2}{*}{ Male } & $\%$ & $58.0 \%$ & $50.0 \%$ & $56.7 \%$ \\
\cline { 2 - 5 } & Count & $\mathbf{1 0 0}$ & $\mathbf{2 0}$ & $\mathbf{1 2 0}$ \\
\cline { 2 - 5 } & $\mathbf{1 0 0 0}$ & $\mathbf{1 0 0 . 0} \%$ & $\mathbf{1 0 0 . 0} \%$ \\
\hline
\end{tabular}

Table 1. Association Between Gender and Patient Groups

Pearson Chi Square $=0.434, \mathrm{df}=1, \mathrm{P}$ value $=0.510$ Non-Significant

The above table shows the Pearson Chi square test value for the association between the gender and the patient's group.

\begin{tabular}{|c|c|c|c|c|}
\hline \multirow{2}{*}{\multicolumn{2}{|c|}{ Religion }} & \multicolumn{2}{|c|}{ Group } & \multirow{3}{*}{$\begin{array}{c}\text { Total } \\
94 \\
\end{array}$} \\
\hline & & Retrospective & Prospective & \\
\hline \multirow{2}{*}{ Hindu } & Count & 76 & 18 & \\
\hline & $\%$ & $76.0 \%$ & $90.0 \%$ & $78.3 \%$ \\
\hline \multirow[b]{2}{*}{ Muslim } & Count & 24 & 2 & 26 \\
\hline & $\%$ & $24.0 \%$ & $10.0 \%$ & $21.7 \%$ \\
\hline \multirow{2}{*}{ Total } & Count & 100 & 20 & 120 \\
\hline & $\%$ & $100.0 \%$ & $100.0 \%$ & $100.0 \%$ \\
\hline \multicolumn{5}{|c|}{ Table 2. Association Between Religion and Patient Groups } \\
\hline \multicolumn{5}{|c|}{$\begin{array}{c}\text { Pearson Chi Square }=1.925, \mathrm{df}=1, \\
\mathrm{P} \text { value }=0.165 \text { Non-Significant }\end{array}$} \\
\hline
\end{tabular}

The above table shows the Pearson Chi square test value for the association between the religion and the patient's group.

\begin{tabular}{|c|c|c|c|c|}
\hline \multirow{2}{*}{\multicolumn{2}{|c|}{ Education }} & \multicolumn{2}{|c|}{ Group } & \multirow{3}{*}{$\begin{array}{c}\text { Total } \\
76 \\
\end{array}$} \\
\hline & & \multirow{2}{*}{$\begin{array}{c}\text { Retrospective } \\
68\end{array}$} & \multirow{2}{*}{$\begin{array}{c}\text { Prospective } \\
8\end{array}$} & \\
\hline & Count & & & \\
\hline Illiterate & $\%$ & $68.0 \%$ & $40.0 \%$ & $63.3 \%$ \\
\hline \multirow{2}{*}{ Primary } & Count & 32 & 12 & 44 \\
\hline & $\%$ & $32.0 \%$ & $60.0 \%$ & $36.7 \%$ \\
\hline \multirow{2}{*}{ Total } & Count & 100 & 20 & 120 \\
\hline & $\%$ & $100.0 \%$ & $100.0 \%$ & $100.0 \%$ \\
\hline \multicolumn{5}{|c|}{ Table 3. Association Between Education and Patient Groups } \\
\hline \multicolumn{5}{|c|}{ Pearson Chi Square $=5.627, \mathrm{df}=1, \mathrm{p}$ Value $=0.018$ Significant } \\
\hline
\end{tabular}

The above table shows the Pearson Chi square test value for the association between the Education and the patient's group.

\begin{tabular}{|c|c|c|c|c|}
\hline \multirow{2}{*}{\multicolumn{2}{|c|}{ Liver }} & \multicolumn{2}{|c|}{ Group } & \multirow{3}{*}{$\begin{array}{c}\text { Total } \\
120 \\
\end{array}$} \\
\hline & & Retrospective & Prospective & \\
\hline \multirow{2}{*}{ Yes } & Count & 100 & 20 & \\
\hline & $\%$ & $100 \%$ & $100 \%$ & $100 \%$ \\
\hline \multirow{2}{*}{ Total } & Count & 100 & 20 & 120 \\
\hline & $\%$ & $100.0 \%$ & $100.0 \%$ & $100.0 \%$ \\
\hline \multicolumn{5}{|c|}{ Table 4. Association Between Liver and Patient Groups } \\
\hline \multicolumn{5}{|c|}{ a. No statistics are computed because Liver is a constant } \\
\hline
\end{tabular}




\begin{tabular}{|c|c|c|c|c|}
\hline \multirow{2}{*}{\multicolumn{2}{|c|}{ Single/Multiple }} & \multicolumn{2}{|c|}{ Group } & \multirow{3}{*}{$\begin{array}{c}\text { Total } \\
7\end{array}$} \\
\hline & & Retrospective & Prospective & \\
\hline \multirow{2}{*}{ Multiple } & Count & 7 & 0 & \\
\hline & $\%$ & $7.0 \%$ & $0.0 \%$ & $5.8 \%$ \\
\hline \multirow{2}{*}{ Single } & Count & 93 & 20 & 113 \\
\hline & $\%$ & $93.0 \%$ & $100.0 \%$ & $94.2 \%$ \\
\hline \multirow{2}{*}{ Total } & Count & 100 & 20 & 120 \\
\hline & $\%$ & $100.0 \%$ & $100.0 \%$ & $100.0 \%$ \\
\hline
\end{tabular}

Table 5. Association Between Single/Multiple and Patient Groups

Pearson Chi Square $=1.487, \mathrm{df}=1, \mathrm{P}$ value $=0.223$ Non-Significant

The above table shows the Pearson Chi square test value for the association between Single/ Multiple and the patient's group.

\begin{tabular}{|c|c|c|c|c|}
\hline \multirow{2}{*}{\multicolumn{2}{|c|}{ Complicated }} & \multicolumn{2}{|c|}{ Group } & \multirow{2}{*}{ Total } \\
\hline & & Retrospective & Prospective & \\
\hline \multirow{2}{*}{ No } & Count & 95 & 19 & 114 \\
\hline & $\%$ & $95.0 \%$ & $95.0 \%$ & $95.0 \%$ \\
\hline \multirow{2}{*}{ Yes } & Count & 5 & 1 & 6 \\
\hline & $\%$ & $5.0 \%$ & $5.0 \%$ & $5.0 \%$ \\
\hline \multirow{2}{*}{ Total } & Count & 100 & 20 & 120 \\
\hline & $\%$ & $100.0 \%$ & $100.0 \%$ & $100.0 \%$ \\
\hline \multicolumn{5}{|c|}{ Table 6. Association Between Complicated and Patient Groups } \\
\hline \multicolumn{5}{|c|}{ Pearson Chi Square $=0.000, \mathrm{df}=1, \mathrm{P}$ value $=1.000$ Non-Significant } \\
\hline
\end{tabular}

The above table shows the Pearson Chi square test value for the association between Complicated and the patient's group.[6]

\section{RESULTS}

In our study $56.7 \%$ patients were males while the rest were females. $78.3 \%$ of patient were Hindu while $21.7 \%$ were Muslim. The disease was more common in illiterate population (63.3\% of total patients).

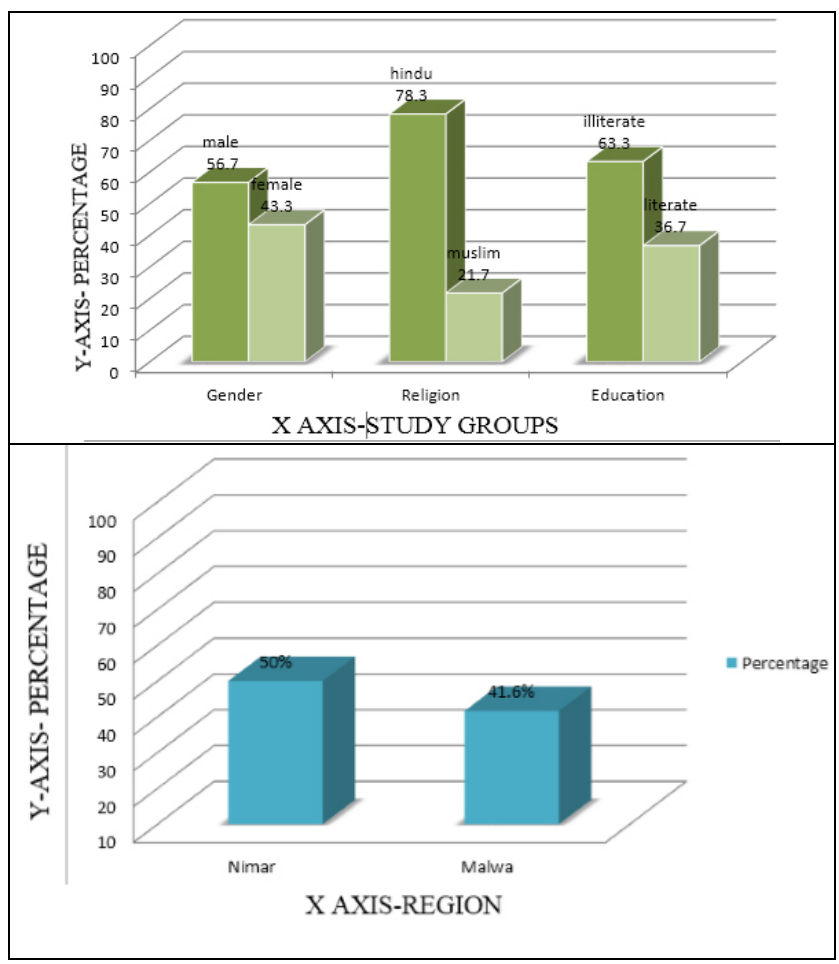

The liver was the most common organ affected with $100 \%$ of cases showing disease. In liver the right lobe was involved in all cases whereas in $5.8 \%$ of cases both lobes were involved. Biochemical studies revealed a raised LFT in $5.8 \%$ of cases while it was within normal limits in $94.2 \%$ cases.

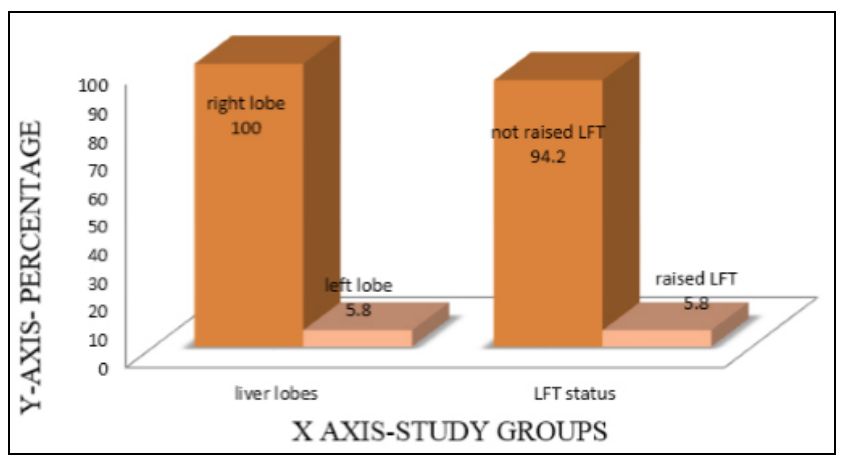

In retrospective cases due to late presentation of patients mainly due to illiteracy and ignorance towards initial symptoms only $9 \%$ of patients could be managed conservatively.[7] These stats increased to $15 \%$ patient treated with medical therapy in prospective group due to increased awareness towards symptoms and early diagnosis.

\section{DISCUSSION}

In our study total 120 cases had been taken, out of which 100 cases are retrospective and 20 cases are prospective. The lowest and highest age group infected were between 20-30 yr and more than 60 yrs. respectively. In our study, young adults and middle-aged individuals made up the largest proportion of surgical cases.

In this study, more than half of the subjects were men and were from rural area. Reasons such as eating raw vegetables, 
close contact with domestic animals and poor hygiene were the major factors affecting disease causation.

Higher prevalence of disease in rural areas especially in district of Nimar region as compared with Malwa region was found because of close contact with soil, cattle, and dogs. In urban areas it is related to lifestyle of the population in which poor hygiene and unhealthy eating behaviors leading to hydatidosis are common. In our study we found that the mean incidence of Hydatid disease patient admitted in general surgical wards is 1.256 per 1000 admissions in general surgical wards.

The disease is more prevalent among illiterate people because of more contact with cattle, poor hygiene and sanitation. It is believed that in our sub-continent with lack of proper sanitation, the infestation of hydatid disease is more common due to ingestion of water or vegetables contaminated by the excreta of carriers and is not so frequently attributable to direct contact of the patient with the infested dog.

Abdominal pain is the most common presentation whereas lump in abdomen is second most common. The patient residing in rural area because of their ignorance usually tend to neglect an asymptomatic lump in the abdomen which does not cause any problem in their daily routine activities. When this lump gets symptomatic, they tend to seek medical advice.

In our study maximum number of patients presented to the hospital within 6 months of appearance of their symptoms. Pulmonary hydatid patients presented early as compared to hepatic hydatid.

Liver is the most common site of hydatid cyst disease and mostly cysts are located in the right lobe. Hydatid cysts can be solitary or multiple. Imaging findings depend on the stage of cyst growth. In our study Jaundice and raised LFT usually seen in very less number of patients who eventually proved to have biliary communication with their cyst or infection. The results of most laboratory screening examinations are usually normal. The diagnosis can be confirmed when radiological imaging (X-RAY USG \&CT SCAN) is combined with serological tests.[8][9]. But serological test was not available in our case.[10] CT Abdomen finding included simple or multicystic round lesion with water attenuation with ring like pattern of calcification in lobes of liver. Size, site, cyst wall thickening, intrahepatic or extra hepatic ruptured of hydatid cyst, subdiaphragmatic collection portal vein involvement is seen.[11] The most common finding on plain $\mathrm{x}$ rays were calcification of cyst wall or in the case of concomitant pulmonary disease, cystic shadows in the lung fields. Calcification is usually curvilinear or ring like and involves the pericyst[12][13].

\section{CONCLUSION}

1. Incidence of hydatid disease in M. Y. Hospital Indore is 1.256 per 1000 admissions in general surgical wards.

2. In our study, high prevalence is seen from the district of Nimar as compared to Malwa region because of more contact with cattle, low level education, poor sanitation and poor hygiene.

3. Disease mostly affects the liver and that too the right lobe of liver and less to left lobe of liver and when left lobe is involved right lobe is usually involved and often multiple lesions are seen.
4. CECT of abdomen can be used as a tool for guiding the approach towards surgery for assessment of depth of cyst, relation with biliary channels and venous system, hence ease of laparoscopic approach.[14][15]

5. Laparoscopic surgical treatment is considered as safe and offers better results for the management of hydatid disease in liver.[16][17]

6. As with other zoonotic diseases, prevention plays an important role in the overall management of this disease. Proper education, creating awareness, deworming of dogs and implementing strict rules regarding the disposal of the remains of slaughtered animals can help in eradicating this disease.

\section{REFERENCES}

[1] Schaefer JW, Khan MY. Echinococcosis (Hydatid disease): lessons from experience with 59 patients. Rev Infect Dis 1991;13(2):243-7.

[2] Barros JL. Hydatid disease of the liver. Am J Surg 1978;135(4):597-600.

[3] Balik AA, Basoglu M, Celebi F, et al. Surgical treatment of hydatid disease of the liver: review of 304 cases. Arch Surg 1999;134(2):166-9.

[4] Demirci S, Eraslan S, Anadol E, et al. Comparison of the results of different surgical techniques in the management of hydatid cysts of the liver. World J Surg1989;13(1):88-91.

[5] WHO Informal Working Group on Echinococcosis: Guidelines for treatment of cystic and alveolar echinococcosis in humans. Bull World Health Organ 1996;74(3):231-42.

[6] Belghiti J, Benhamou JP, Houry S, et al. Caustic sclerosing cholangitis: a complication of the surgical treatment of hydatid disease of the liver. Arch Surg 1986;121(10):1162-5.

[7] Tasev V, Dimitrova V, Draganov K, et al. Hepatic echinococcosis: radical or conservative surgical treatment. Khirurgiia (Sofiia) 2002;58(2):10-3.

[8] Gharbi HA, Hassine W, Brauner MW, et al. Ultrasound examination of the hydatic liver. Radiology 1981;139(2):459-63.

[9] Lewall DB, McCorkell SJ. Hepatic echinococcal cysts: Sonographic appearance and classification. Radiology 1985;155(3):733-5.

[10] Kagan IG. A review of serological tests for the diagnosis of hydatid disease. Bull WHO 1968;39(1):25-37.

[11] Kalovidouris A, Voros D, Gouliamos A, et al. Extracapsular (satellite) hydatid cysts. Gastrointest Radiol 1992;17(4):353-6.

[12] Dogan R, Yuksel M, Cetin G, et al. Surgical treatment of hydatid cysts of the lung: report on 1055 patients. Thorax 1989;44(3):192-9.

[13] Kilani T, El Hammami S, Horchani H, et al. Hydatid disease of the liver with thoracic involvement. World J Surg 2001;25(1):40-5.

[14] Langer JC, Rose DB, Keystone JS, et al. Diagnosis and management of hydatid disease of the liver. A 15-year North American experience. Ann Surg 1984;199(4):412-7. 


\section{Jemds.com}

[15] Ekrami Y. Surgical treatment of hydatid disease of the liver. Arch Surg 1976;111(12):1350-2.

[16] Magistrelli P, Masetti R, Coppola R, et al. Surgical treatment of hydatid disease of the liver. A 20-year experience. Arch Surg 1991;126(4):518-22, discussion 523.
Original Research Article

[17] Sayek I, Yalin R, Sanac Y. Surgical treatment of hydatid disease of the liver. Arch Surg 1980;115(7):847-50. 